\title{
Monitoring of long-term changes in GBAS daily solutions for the maintenance of the Polish reference frame
}

\author{
Karolina Szafranek, Andrzej Araszkiewicz, Janusz Bogusz, Marusz Figurski \\ Faculty of Civil Engineering and Geodesy, Military University of Technology, Kaliskiego 2, Warsaw 00-908, Poland
}

\begin{abstract}
The paper deals with the problem of the reliability of reference systems realized by the permanent GNSS (Global Navigation Satellite System) networks. The GNSS technique is used for realization of global reference system ITRS (International Terrestrial Reference System), (e.g. ITRF2008 - International Terrestrial Reference Frame) and European reference system ETRS89 (European Terrestrial Reference System), (ETRF2000 - European Terrestrial Reference Frame). In 2012 Polish government introduced the PL-ETRF2000 frame, which is realized in practice by the selected number of EPN (EUREF Permanent Network) stations. There are also some accuracy criteria $(0.01 \mathrm{~m}$ for horizontal position and $0.02 \mathrm{~m}$ for vertical component) related to the role of ASG-EUPOS (Active Geodetic Network - European Position Determination System, Polish GBAS (Ground Based Augmentation System)) as the fundamental and base geodetic networks.

In the frame of ASG+ project ("The supporting modules for ASG-EUPOS system real-time services") coordinates monitoring module has been developed. Its main goal is to investigate the reliability of instantaneous ASG-EUPOS coordinates obtained using various IGS products (final, rapid, ultra rapid) by comparing them to the reference values. The paper focuses on the method of final solutions determination as they are the most reliable ones and which delay (about 2 weeks) is acceptable for reference frame monitoring purpose. This fully automatic module enables analysis of instantaneous and archive coordinates to estimate the stability of each station's position and the reliability of the whole reference frame. As the independent element the graphical presentation serves. This can be found at the web page of the Centre of Applied Geomatics (CAG) at www.cgs.wat.edu.pl.

Despite the fact that the module has been developed for Polish national system, its construction is general and could be used for monitoring of other GNSS networks.
\end{abstract}

Keywords: GNSS; reference station; monitoring, ASG-EUPOS.

\section{Introduction}

Nowadays, GNSS (Global Navigation Satellite System) permanent networks play a crucial role in geodesy. Besides using GNSS technique for surveying i.e. determination of points coordinates for engineering purposes, one of its most important application is reference system realization. Permanent GNSS networks enables gathering data from a long time interval and they serve as a reference for satellite differential measurements.

In Poland, current law introduces the PL-ETRF2000 (European Terrestrial Reference Frame) reference frame [11]. The EPN (EUREF Permanent Network) stations are its materialization, while permanent GNSS stations belonging to the ASGEUPOS (Active Geodetic Network - European Position Determination System) transfer it to the territory of Poland and ensure its maintenance. As a consequence, the coordinates of these stations should fulfil some specific accuracy criteria (in general it means that the error of their position should not exceed 0.01 meter for horizontal components and 0.02 meter for ellipsoidal height). The detailed description of Polish geodetic networks (fundamental, base and measurement) and the criteria that should be fulfilled by station belonging to each group were presented in [1].

The significant importance of GNSS stations in modern geodesy is out of any discussions. This results in the necessity of its monitoring and permanent control, as their malfunction can affect all geodetic measurements made with reference to these stations. Long-term problems occurring at GNSS permanent stations decrease the reliability and accuracy of reference frame maintained by them.

Corresponding author: Karolina Szafranek. E-mail address: kszafranek@wat.edu.pl

http://dx.doi.org/10.3846/enviro.2014.249

(C) 2014 The Authors. Published by VGTU Press. This is an open-access article distributed under the terms of the Creative Commons Attribution License, which permits unrestricted use, distribution, and reproduction in any medium, provided the original author and source are credited. 
Besides official Polish GBAS (Ground Based Augmentation System) - ASG-EUPOS [13] managed by HOGC (Head Office of Geodesy and Cartography) - there are also permanent networks managed by private companies. As their main purpose is to provide commercial services to the surveyors, they also have to meet the criteria introduced by law [12]. Satellite data gathered by these stations can be used for the scientific purpose e.g. for geodynamical studies [2, 3], or to determine troposphere parameters [4].

The Centre of Applied Geomatics at the Military University of Technology (Warsaw, Poland) conducts monitoring of almost 350 permanent stations located at the territory of Poland and foreign stations situated near Polish borders. The purpose is to control stations long-term behaviour in the context of reference frame maintenance and for the assessment of the solutions stability and to investigate their short-term activity mainly to ensure reliable temporary reference and check if the station is not affected by any disturbances. The methodology of reference coordination determination, the strategy of the processing made using Bernese software [10] and the scheme of the whole monitoring system was described in details in [5]. Once in a while (e.g. every time when reference frame ETRF2000 (European Terrestrial Reference Frame) is updated), the reference solution is newly calculated with new data and updated models taken into consideration. The GNSS data processing is made using three types of the IGS products: final, rapid and ultra-rapid [14]. The results (coordinates) obtained with the delay related to the type of products are compared with the reference values determined on the basis of long observations by cumulating weekly solutions. The discrepancies between the current and reference values are published online [15] in the form of diagrams.

\section{Monitoring of long-term changes}

There are several long-term factors that can disturb solutions from permanent GNSS stations and, as a consequence, they have an impact on the quality of reference frame maintained by these stations. Time series of coordinates can be affected by oscillations (annual and semi-annual [6]), discontinuities related to the equipment change, outliers caused e.g. by snow cover [7] or by residual linear trend, which stands for the stations velocity. All of them cause the differences between temporary coordinates and the catalogue ones used as a reference. Within the long time, they result in reference frame deformation and decrease of its reliability. Within the short time they will affect the satellite differential measurements made with reference to these stations.

Poland lies on the relatively stable part of Eurasian plate. Because of that no significant temporary changes in the time series are occurred. The intraplate velocities of GNNS stations are very stable, furthermore they are at the level of a few millimetres per year. Some problems occur at stations located near mining areas. For analysis aimed at assessing the reference frame quality, daily solutions determined with IGS final product were used. All coordinates are expressed in the ETRF2000(R08), for better interpretative purposes and to be consistent with the law-requirements these coordinates were transformed into topocentric (North-East-Up) components.
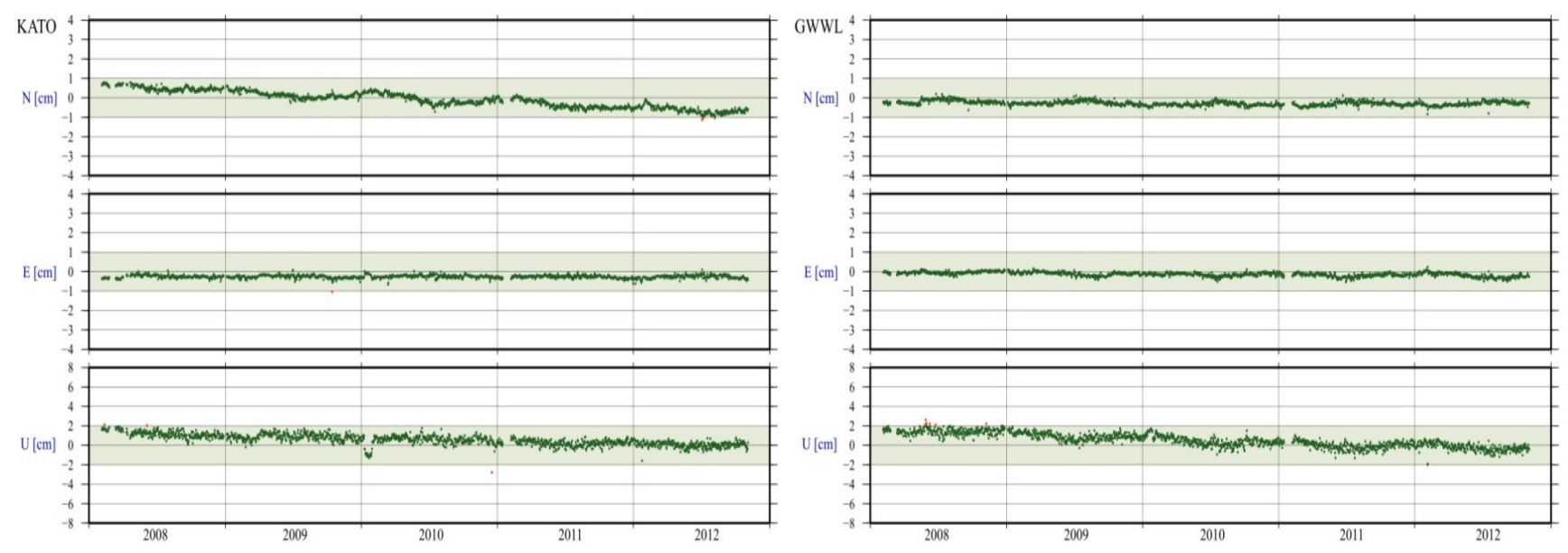

Fig. 1. Time series of daily topocentric KRAW (a) and GWWL (b) coordinates determined using final IGS products

In the context of reference frame maintenance, non-zero velocities causes changes between coordinates describing real stations (antenna reference point) location and their reference (catalogue values). The study of this problem for all ASGEUPOS stations was described in details in [1]. The problem is extremely important for the fundamental stations, as the requirements concerning their accuracy are the highest ( 1 centimetre of horizontal and 2 centimetres for vertical components). The examples are given in Fig. 1. Figure 1a presents time series of KATO (Katowice) coordinates, where strong linear trend for North component can be observed and station GWWL (Gorzów Wielkopolski, Poland), where the $U p$ component changes significantly with time. Within next few months/years the criteria will be exceeded and the catalogue values should be corrected to reflect the instantaneous positions. Otherwise, the reference frame will be affected by small, but systematic distortion. 
One of the best examples of the monitoring necessity are times series of STRG (Starogard Gdański, Poland) station (Fig. 2a). Since the beginning of the ASG-EUPOS in 2008 up to 2010 the improper stabilization of the antenna was causing high scatter of its coordinates observed mainly for horizontal components. The manager of the system improved the antenna mounting and since that time the precision of coordinates increased.
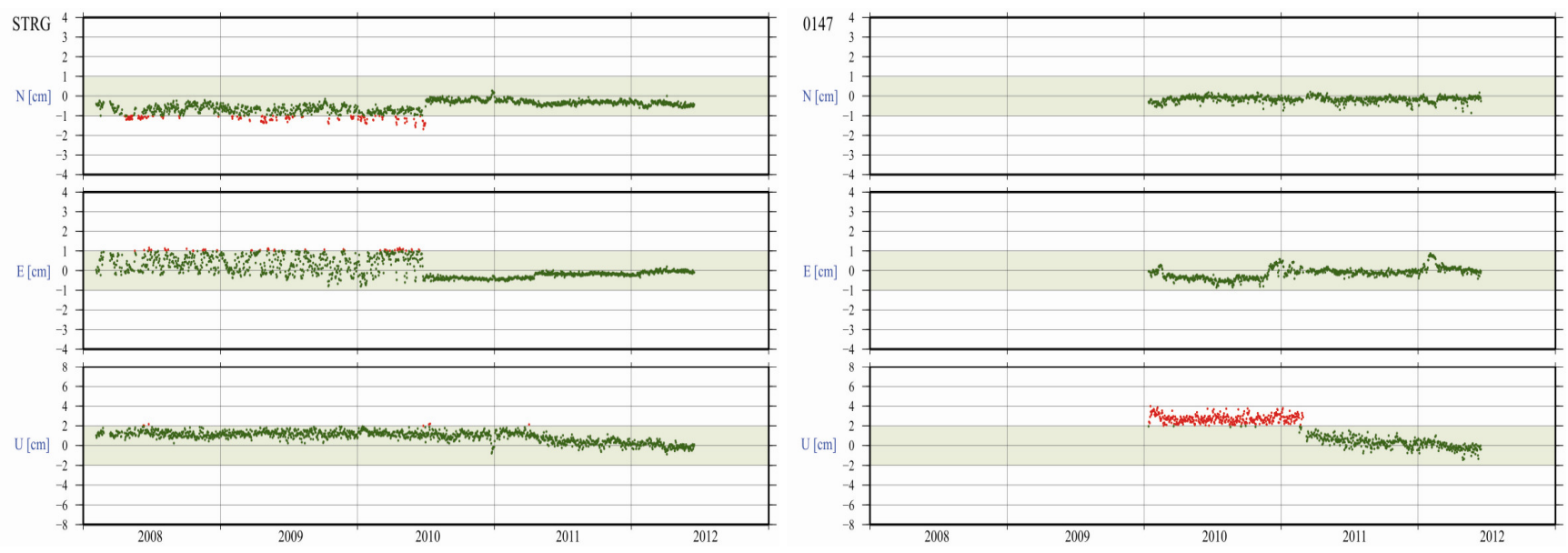

Fig. 2. Time series of daily topocentric STRG (a) and 0147 (b) coordinates determined using final IGS products

Another problem proving the need of monitoring is presented on Fig. 2b. The discontinuity at the beginning of 2011 was caused by the equipment (antenna) change. Although it was taken into consideration during processing, the $U p$ component changed by about 2 centimetres. The reference coordinates were determined independently for two periods. The new values of coordinates are the reference on Fig. $2 b$, that is why the previous solutions exceed the accuracy criteria and are marked with red. In general, after the equipment change (it concerns especially antennas) the station should be temporary excluded from the system until the new cumulative solution is determined.
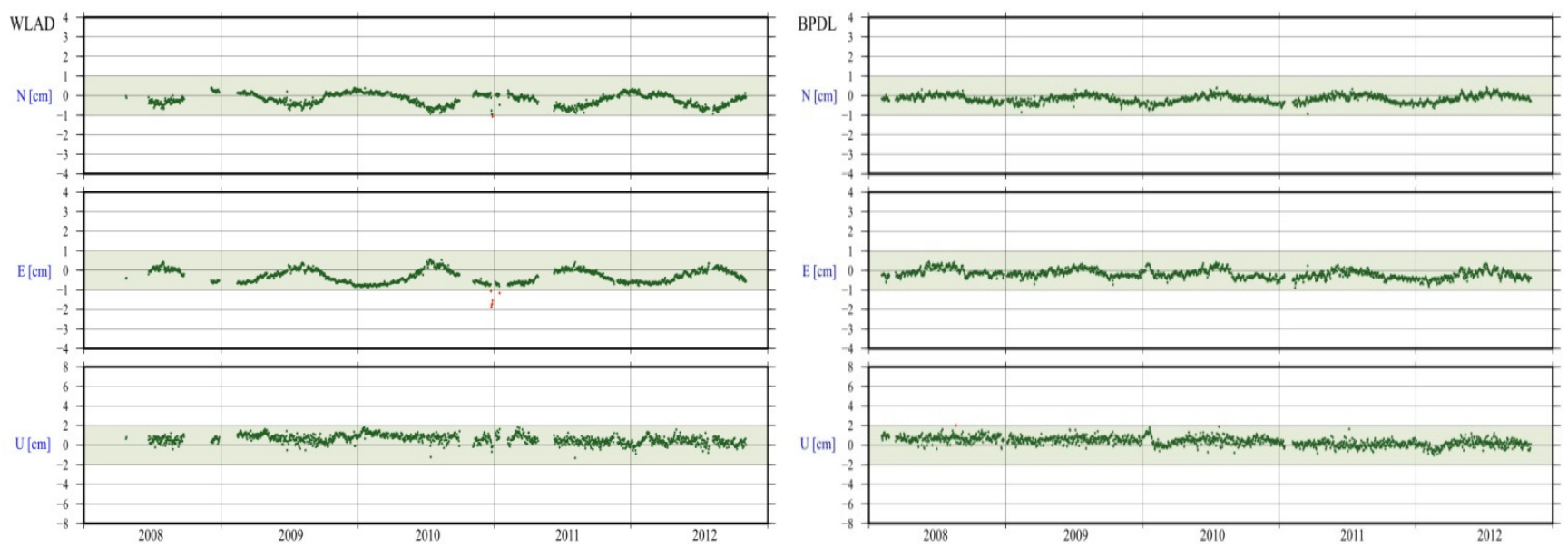

Fig. 3. Time series of daily topocentric WLAD (a) and BPDL (b) coordinates determined using final IGS products

The examples of annual oscillations in time series are presented on Fig. 3. The calculations were made using TSView software [8]. Figure 3a presents WLAD (Władysławowo) stations located at the breakwater, so the strong oscillations observed in horizontal components can be justified by the nearness of the Baltic Sea. The oscillations however do not cause exceeding of the accuracy criteria. The special care should be put on this stations, because of its non-zero residual velocity (which uncertainty is related to the oscillations). The imposition of these two effect can magnify the differences between the temporary and reference coordinates. Some oscillation with smaller amplitude can be also seen (especially for North component) in daily time series of BPDL (Biała Podlaska, Poland) on Fig. 3b. The values of annual and semi-annual amplitudes for all ASG-EUPOS stations are presented consequently in Fig. 4 and Fig. 5. 

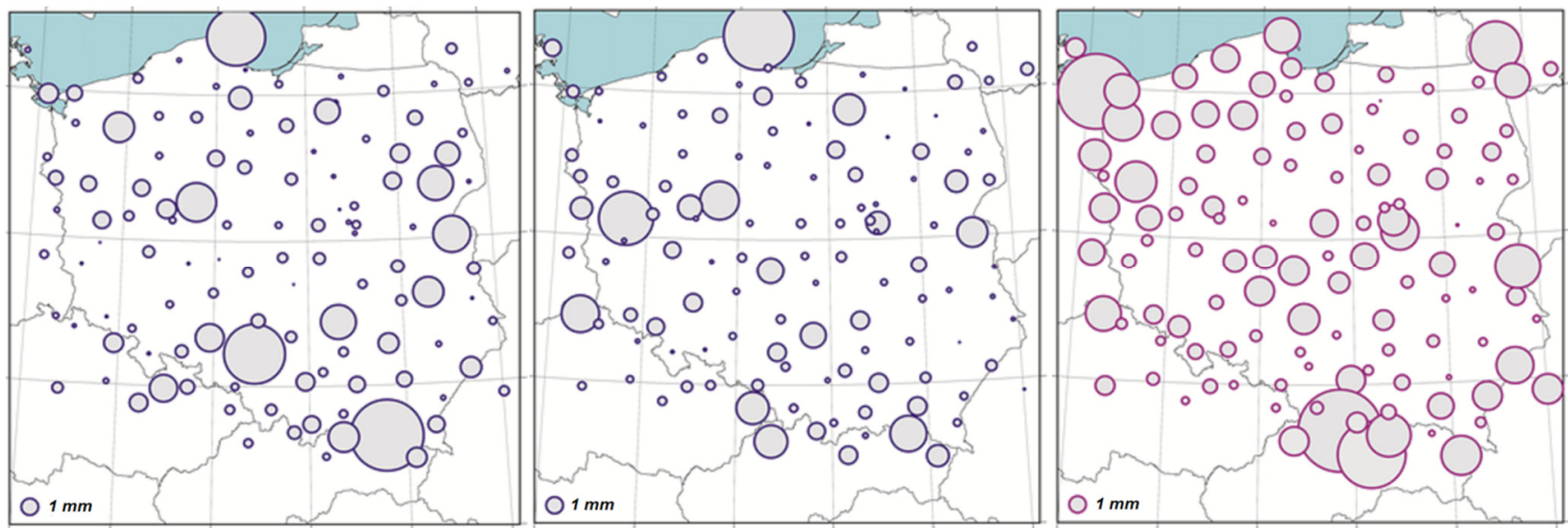

Fig. 4. Annual oscillations of all ASG-EUPOS stations for North (a), East (b) and Up (c) components
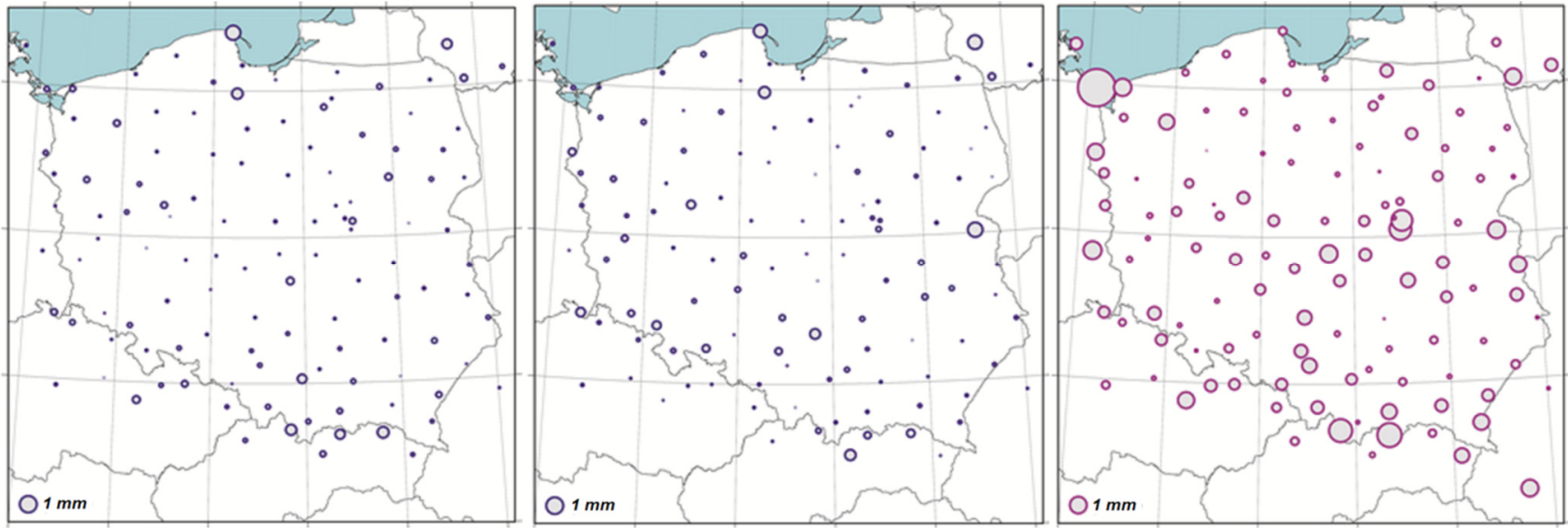

Fig. 5. Semi-annual oscillations of all ASG-EUPOS stations for North (a), East (b) and Up (c) components

Amplitudes of annual oscillation are significantly higher than amplitudes of semi-annual oscillations, but none of them can be characterized with the systematic geographical distribution. Thermal changes or artefacts are the most probable reason of annual oscillations, but their interpretation has secondary meaning in the context of reference frame maintenance. The most important is to estimate the impact on the coordinates accuracy. The amplitude of the annual oscillation of horizontal components is below 5 millimetres for all stations. For vertical component this value is slightly exceeded only for LIE1 (Liesek, Slovakia) station. The values of semi-annual amplitudes are much smaller, for horizontal components they do not exceed 1 millimetre and for vertical component -2 millimetres (the only exception is 0781 (Ahlbeck, Germany) station, where the amplitude of semi-annual oscillation for $U p$ component reaches 2.3 millimetres). This means that the oscillations are not serious threat for the accuracy criteria, but the solutions (coordinates) should be monitored to verify this. For that reason the velocities determined for geodynamical purposes [9] have to be determined in the robust way.

Another reason of disturbances of GNSS coordinates is caused by snow cover. For the majority of Polish stations some outliers can be noticed during winter seasons. They correspond to heavy snowfalls and very often cause temporal exceeding of accuracy demands. The exemplary time series of LODZ (Lodź, Poland) station are shown in Fig. 6a. Several horizontal solutions (mainly East and Up component) in the beginning of 2010 differed of about consequently 5 and 15 millimetres from the catalogue values. During next winter in 2011 the disturbances were so strong that they did not allow to determine coordinates. Figure $6 \mathrm{~b}$ presents map of the ASG-EUPOS stations from the January 2013. It can be seen that the accuracy criteria were exceeded by several stations (they are marked with red). In that day the heavy snowfalls occurred in Poland. This effect can be mainly observed for the stations located in the southern part of Poland, where the snowfall was stronger than in other parts of the country.

Single disturbances will not have serious impact on the temporal reference frame maintenance, because the position of the measured point is usually referred to a few stations (network solution). The possibility of reliability decrease is related to the situation, when, as a result of the same disturbance factors, several stations give solutions with lower accuracy (Fig. 6b). It can cause systematic errors in differential measurements. This effect cannot be eliminated, but it can be monitored to consciously asses its impact on the measurements. 

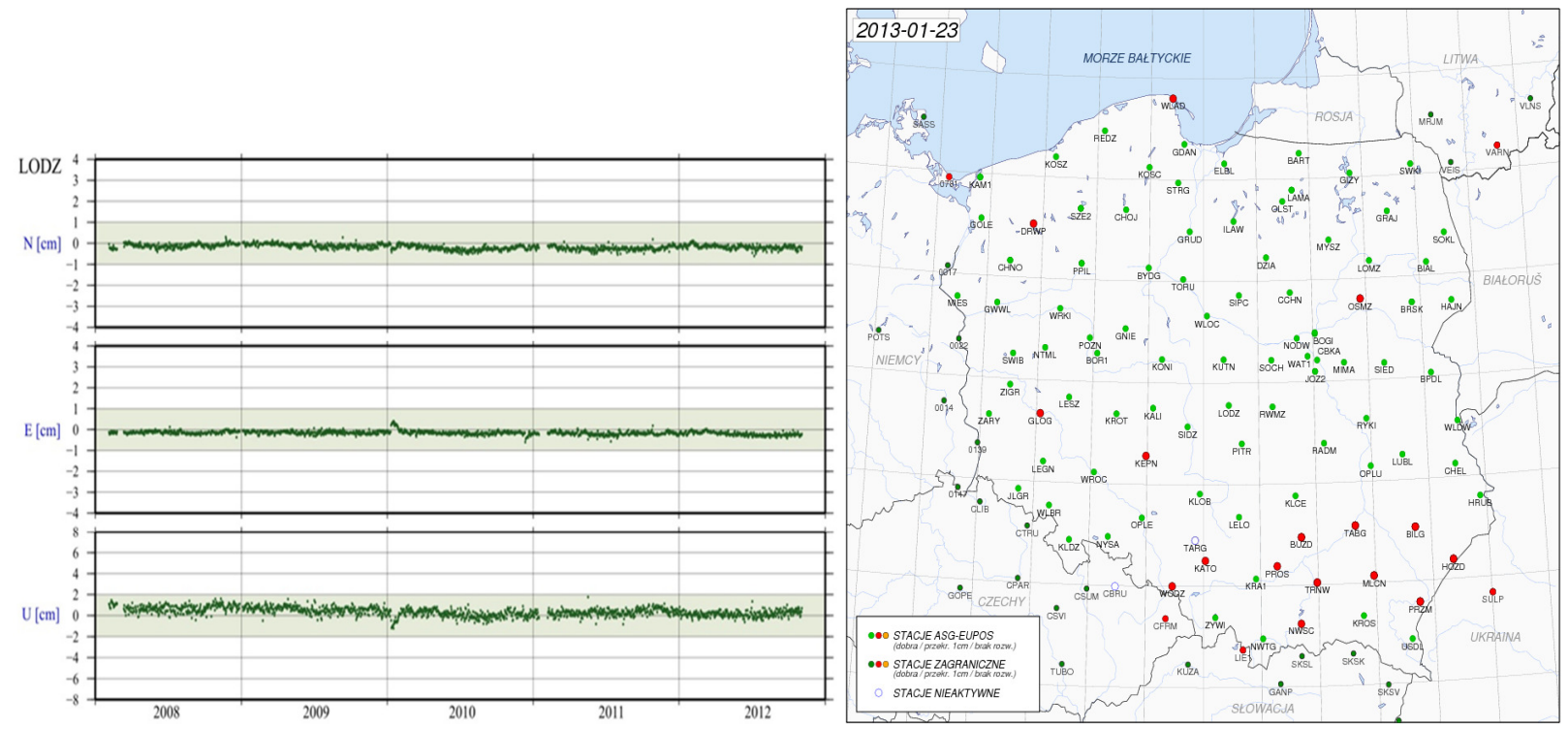

Fig. 6. The exemplary time series, where outliers related to the snowfall can be observed (LODZ station, a). On the right (b) map of the ASG-EUPOS stations from the January 2013 (stations marked with red were affected by the heavy snowfall)

Table 1. The extreme values of NEU components of ASG-EUPOS fundamental stations (15). The analysis were made on the basis of the results of processing made for the GPS weeks 1465-1712 (from February 2008 to November 2012)

\begin{tabular}{ccccccc}
\hline & $\mathbf{N}_{\min }[\mathrm{cm}]$ & $\mathbf{N}_{\max }[\mathrm{cm}]$ & $\mathbf{E}_{\min }[\mathrm{cm}]$ & $\mathbf{E}_{\max }[\mathrm{cm}]$ & $\mathbf{U}_{\min }[\mathrm{cm}]$ & $\mathbf{U}_{\max }[\mathrm{cm}]$ \\
\hline BOGI & -0.5 & 0.2 & -0.6 & 0.0 & -1.0 & 1.6 \\
BOR1 & -2.5 & 0.2 & -0.9 & 0.3 & -1.0 & 1.4 \\
BPDL & -0.9 & 0.4 & -0.9 & 0.4 & -1.0 & 2.0 \\
BYDG & -0.5 & 0.3 & -0.6 & 0.1 & -1.0 & 2.1 \\
GWWL & -0.8 & 0.2 & -0.5 & 0.2 & -2.0 & 2.6 \\
JOZ2 & -1.4 & 0.7 & -0.9 & 0.8 & -1.4 & 1.7 \\
KATO & -1.1 & 0.8 & -1.0 & 0.1 & -2.8 & 2.1 \\
KRA1 & -0.8 & 0.1 & -0.5 & 0.2 & 0.1 & 3.7 \\
LAMA & -0.8 & 0.2 & -0.7 & 0.1 & -0.7 & 1.4 \\
LODZ & -0.6 & 0.3 & -0.6 & 0.4 & -1.2 & 1.8 \\
REDZ & -0.5 & 0.9 & -0.6 & 0.7 & -2.6 & 1.7 \\
SWKI & -0.5 & 0.3 & -0.6 & 0.3 & -1.4 & 2.1 \\
USDL & -0.9 & 0.2 & -0.9 & 0.1 & -1.4 & 1.8 \\
WROC & -0.6 & 0.2 & -0.9 & 0.2 & -1.3 & 2.0 \\
ZYWI & -1.7 & 0.3 & -1.1 & 0.9 & -5.6 & 2.0 \\
\hline
\end{tabular}

This monitoring is continuously performed for all GNSS stations. In practice, the differences between fundamental, base and measurement networks are on the level of definitions. The permanent monitoring guarantees the highest quality of the reference frame maintained by all stations gathering the data using GNSS technique. The singular, periodic outliers do not decrease its accuracy, but the long-term analysis of solutions have to be made to have knowledge, when the reference coordinates should be updated.

The summary of the topocentric coordinates analysis made for the assessment of the Polish reference frame quality is presented in Table 1. The lowest and the highest values of $N E U$ components proves that daily solutions determined using final IGS products are characterized with the high precision. The ETRF200 in Poland is realized with the high reliability and stability.

\section{Monitoring of short-term changes}

The delay of final solutions described in the previous chapter is related to the accessibility to the proper IGS products. The final solutions are usually available 7-14 days after the observations, so they can be used for reference frame monitoring, but not for the permanent control of stations correct activity. For this purpose coordinates using rapid and ultra-rapid IGS products are being determined. The rapid solutions are calculated for each day with the delay of about 18 hours, while the ultra-rapid solutions are calculated with temporal resolution of one hour and the delay reaching up to 3 hours. 
The current coordinates are published online [6] on the interactive map (it is shown in Fig. 6b). Green dots correspond to the solutions, which meet the accuracy criteria, the red dots stand for the excess of its values, while orange colour is used to mark the stations with missing data. After selection of station, the user can look at the coordinates in graphical form. The exemplary graphs of rapid solutions are presented in Fig. 7-9. They present coordinates expressed in ETRF2000(R08) reduced to the epoch 2011.0 (black, such epoch was chosen as a reference epoch for the ASG-EUPOS) and coordinates expressed at the epoch of observations (orange). As a reference coordinates determined using final IGS products were used. Figure 7 presents solution, for which accuracy criteria were fulfil, Fig. 8 solution, for which the criteria were exceeded, and finally Fig. 9 time series of station with missing data. For the monitoring of rapid solutions the criteria were set to 1 centimetre for all components.
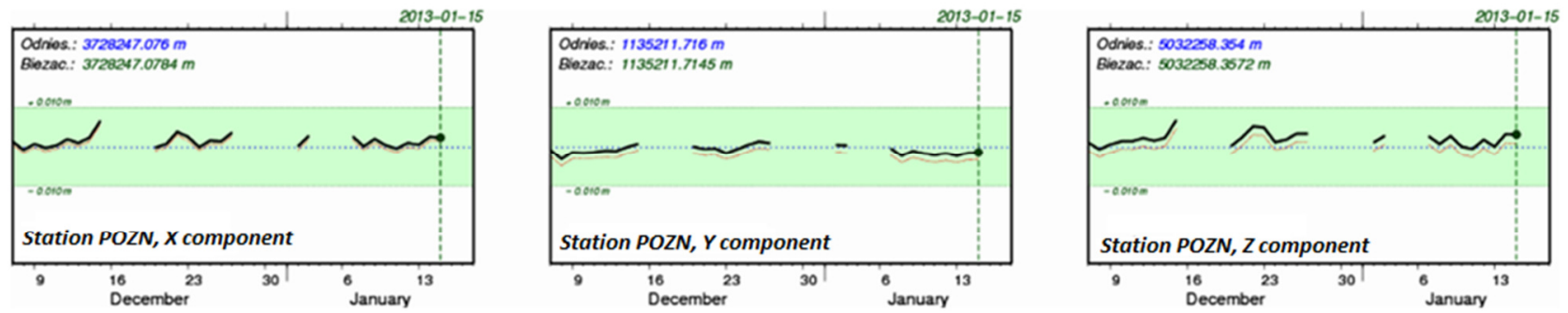

Fig. 7. The exemplary time series of coordinates determined using rapid IGS products. Green colour stands for solutions, which fulfil the accuracy criteria.
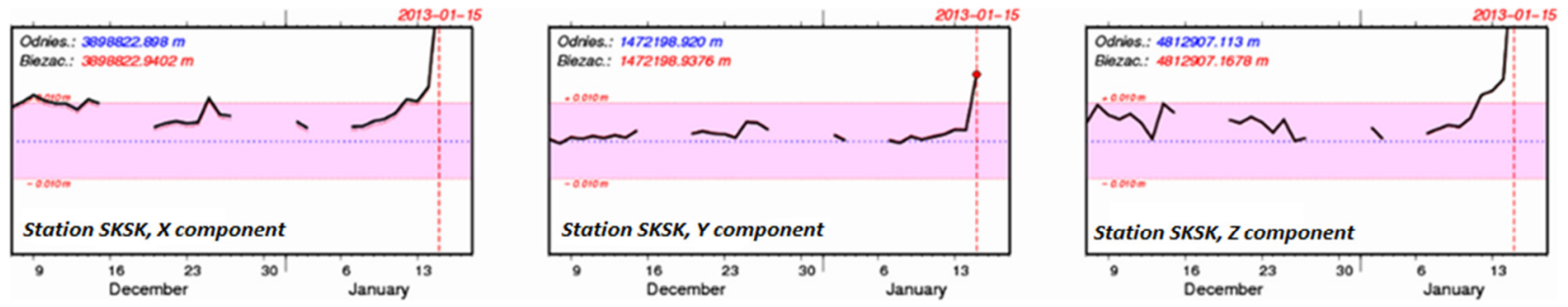

Fig. 8. The exemplary time series of coordinates determined using rapid IGS products. Red colour stands for solutions, which exceed the accuracy criteria
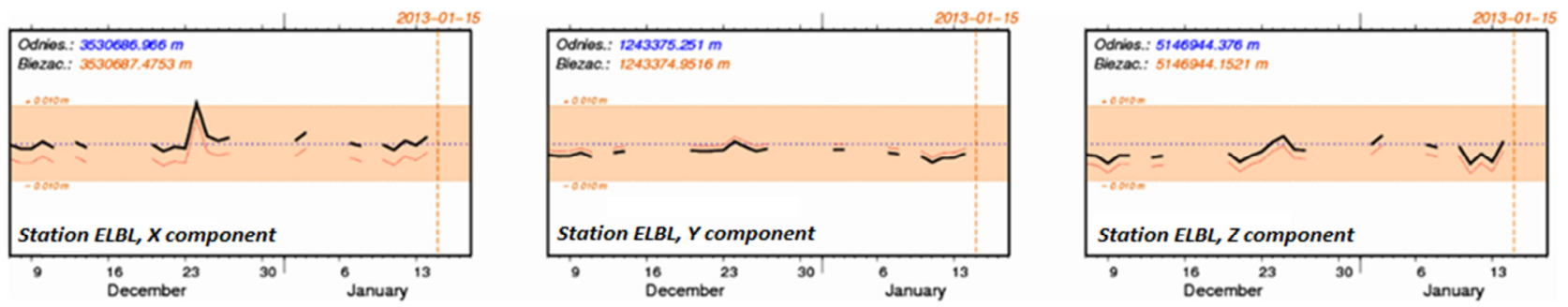

Fig. 9. The exemplary time series of coordinates determined using rapid IGS products. Red colour stands for missing data

Currently the processing using ultra-rapid products is made only for several commercial stations, as the high demands concerning data accessibility, but the system is ready for more stations to be added. The exemplary solutions are presented on Fig. 10. The coordinates are expressed at the epoch of observation and the warning criteria were set to 2 centimetres for each component. The ultra-rapid solutions determined for each hour are marked with blue dots. The black line stands for rapid solutions for the same station. Because of the delay no longer than three hours, they reflect the current position of the GNSS station.

The rapid and ultra-rapid solutions allow to control each station activity and enable quick response of their managers in case of malfunction (e.g. exclusion of misbehaved station from the network). However, because of their lower accuracy and higher scatter they cannot be used for the monitoring of long-term changes in the national reference frame.
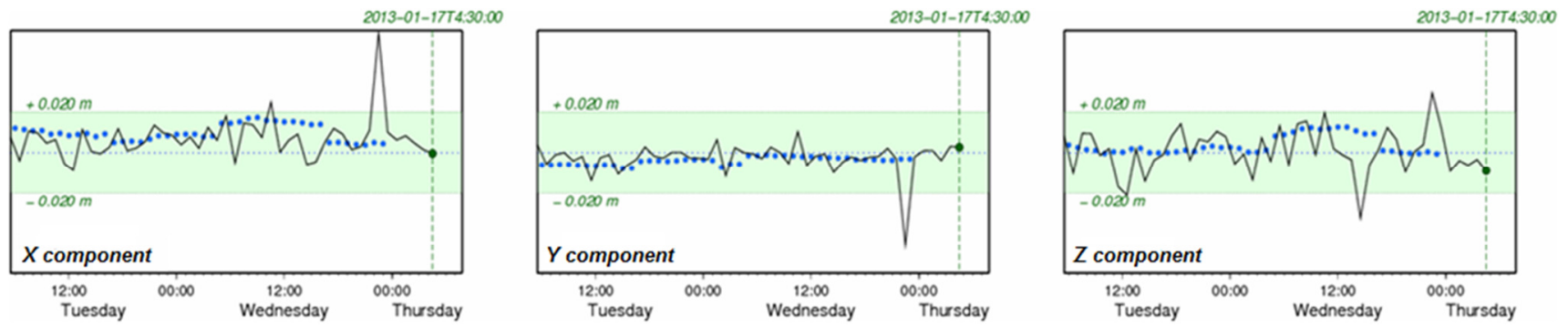

Fig. 10. The exemplary time series of coordinates determined using ultra-rapid IGS products 


\section{Conclusions}

The system of monitoring elaborated in the Centre of Applied Geomatics is fully automated and it controls the coordinates of about 350 stations belonging to various networks (both national and private). Time series of coordinates were obtained using different kinds of IGS products (final, rapid and ultra-rapid) and were compared to the reference values, which describe the stations real position with the highest possible accuracy and reliability. The analysis of these time series proved that periodic control of stations coordinates are not enough for the verification of their quality.

The solutions obtained using final IGS products proves that GNSS stations can play a role of the geodetic network (in Poland fundamental and base) and that they fulfil the criteria specified by Polish law. The ASG-EUPOS is a stable and homogenous geodetic network, which enables the ETRS89 realization on the territory of Poland with the accuracy better than 1 centimetre horizontally and 2 centimetres vertically. Although there are different types of geodetic networks consisting of GNSS stations (fundamental, base and measurement), the analysis of all stations solutions showed that the accuracy and reliability of all permanent stations in Poland is at the same level (it depends of course on the stabilization, external factors like snow cover and equipment). The monitoring of coordinates allow to notice when the reference (catalogue) values do not reflect the real, current position of stations. Necessity of periodic change of the permanent GNSS stations coordinates is the result of the essence of GNSS technique (e.g. change of the equipment), new distributions of global and regional frames taking advantage of the newest data and significant intraplate velocities of stations, which could not be observed without permanent observations.

The permanent monitoring is necessary also to ensure high quality of system reference function. For the fast detection of any abnormalities at particular station it is necessary to monitor its solutions (coordinates) with the shortest possible delay using rapid and ultra-rapid IGS products (delay below three hours). All significant changes in coordinates result in alarming of the stations manager to do the necessary actions. The monitoring system is available online and it can be used by surveyors, who want to plan their measurements or to assess their reliability.

\section{Acknowledgements}

The research was supported by the Faculty of Civil Engineering and Geodesy of the MUT statutory research funds.

\section{References}

[1] Szafranek, K. 2012. The problem of temporal validity of reference coordinates in the context of reliability of the ETRS89 system realization in Poland, Artificial Satellites 47(4): 177-188.

[2] Bogusz, J.; Figurski, M.; Kontny, B.; Grzempowski, P. 2012. Horizontal velocity field derived from EPN and ASG-EUPOS satellite data on the example of south-western part of Poland, Acta Geophysica et Geomaterialia 9(3/167): 349-357.

[3] Bogusz, J.; Figurski, M.; Araszkiewicz, A.; Szafranek, K. 2010. Application of short-time GNSS solutions to geodynamical studies - preliminary results, Acta Geodynamica et Geomaterialia 7(3/159): 295-302.

[4] Hadas, T.; Kaplon, J.; Bosy, J.; Sierny, J.; Wilgan, K. 2013. Near-real-time regional troposphere models for the GNSS precise point positioning technique, Measurement Science and Technology 24(5). http://dx.doi.org/10.1088/0957-0233/24/5/055003

[5] Szafranek, K.; Bogusz, J.; Figurski, M. 2013. GNSS reference solution for permanent station stability monitoring and geodynamical investigations: the ASG-EUPOS case study, Acta Geodynamica et Geomaterialia 10(1/169): 67-75.

[6] Bogusz, J.; Figurski, M. 2014. Annual signals observed in regional GPS networks, Acta Geodynamica et Geomaterialia.

[7] Kłos, A.; Bogusz, J.; Figurski, M.; Kosek, W. 2014. On the handling of outliers in the GNSS time series by means of the noise and probability analysis, in International Association of Geodesy Symposia, proceedings of the IAG Scientific Assembly 2013.

[8] Herring, T. A. 2003. MATLAB Tools for viewing GPS velocities and time series, GPS Solutions 7(3): 194-199. http://dx.doi.org/10.1007/s10291003-0068-0

[9] Bogusz, J.; Kłos, A.; Grzempowski, P.; Kontny, B. 2013. Modelling velocity field in regular grid on the area of Poland on the basis of the velocities of European permanent stations, Pure and Applied Geophysics. http://dx.doi.org/10.1007/s00024-013-0645-2

[10]Dach, R.; Hugentobler, U.; Fridez, P.; Meindl, M. (Eds.). 2007. Bernese GPS Software Version 5.0. User manual, Astronomical Institute, University of Bern.

[11]Rozporzqdzenie Rady Ministrów z dnia 15 października 2012 r. w sprawie państwowego systemu odniesień przestrzennych (Dz.U. 2012, poz. 1247), 2012 (Regulation of the Council of Ministers concerning national spatial reference system), in Polish.

[12] Rozporzqdzenie Ministra Administracji i Cyfryzacji z dnia 14 lutego 2012 roku w sprawie osnów geodezyjnych, grawimetrycznych i magnetycznych (Dz. U. No. 63, poz. 352), 2012 (Regulation of the Minister of Administration and Digitalization concerning geodetic, gravimetric and magnetic networks), in Polish.

[13] http://www.asgeupos.pl/

[14]http://igscb.jpl.nasa.gov/components/prods.html

[15]http://www.cgs.wat.edu.pl 